\title{
O brilho das estrelas apagadas
}

\section{Luiz Francisco Rebello}

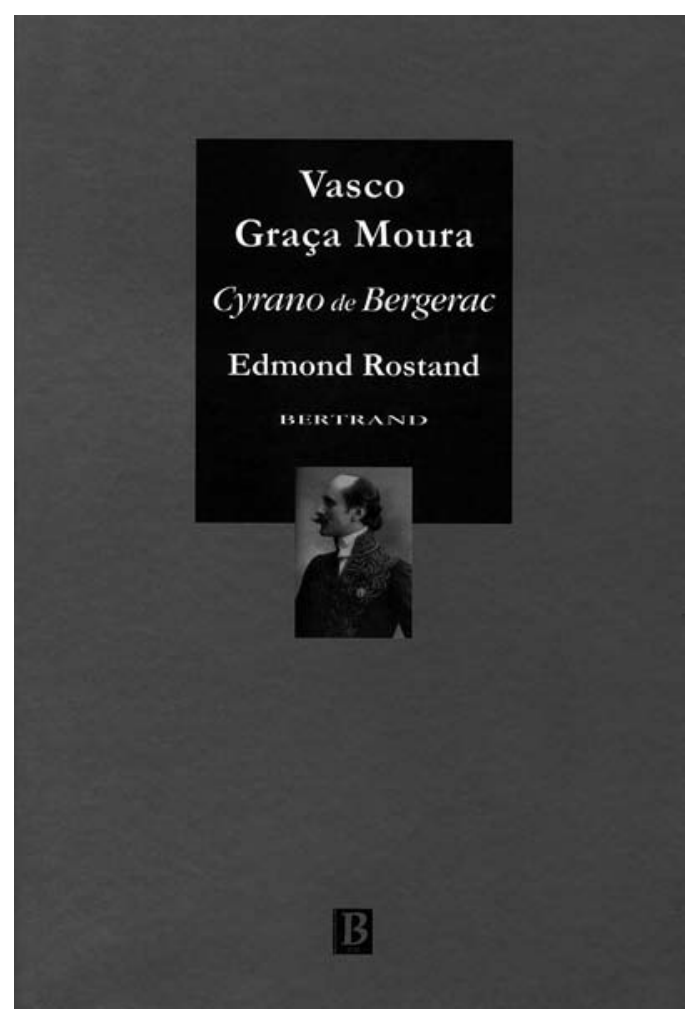

Vasco Graça Moura meteu ombros a uma tarefa diante da qual muitos hesitariam: traduzir, em verso rimado, os alexandrinos sonoros do Cyrano de Bergerac, de Edmond Rostand.

No prefácio da respectiva edição, Graça Moura regista que nalgumas histórias da literatura francesa o nome do seu autor não é sequer citado. Compreende-se. Já numa história do teatro, ou, mais amplamente, das artes do espectáculo, a omissão seria injustificável. A estreia, em 28 de Dezembro de 1897, na vasta sala do Teatro da Ponte St. Martin, onde haviam subido à cena os dramas românticos de Victor Hugo e Alexandre Dumas, da "comédia heróica" de Rostand constituiu um êxito apoteótico, como de poucos haveria, e tornaria a haver, notícia. A critica, com rarissimas excepções - André-Ferdinand Hérold no "Mercure de France", como se recorda no citado prefácio, e Jules Lamaître na "Revue des Deux Mondes" - foi ditirâmbica. Eis o que escreveram Émile Faguet e Francisque Sarcey, os dois mais reputados e influentes cronistas teatrais de então. 0 primeiro, que pedia desculpa de ter achado $04 .^{\circ}$ acto "mais ou menos muito mau", rendeuse ao que considerou ser, e cito, "o verdadeiro estilo, a verdadeira eloquência, a verdadeira emoção, a verdadeira graça, a verdadeira poesia". Por sua vez, Sarcey deu largas

\author{
Edmond Rostand, Cyrano de Bergerac, \\ Trad. Vasco Graça Moura, Lisboa, \\ Bertrand Editora, 2007, 669 p.
}

ao seu júbilo por, e cito também, "vermo-nos finalmente desembaraçados das brumas escandinavas, dos estudos psicológicos demasiado minuciosos e das brutalidades intencionais do drama realista" - para concluir, numa efusão retórica: "Que felicidade! Que felicidade! Eis o jucundo sol da velha Gáulia que, após uma longa noite, renasce no horizonte!" ("La Petite Illustration" 1939: 6364).

Em singular contraste, pouco mais de um ano antes, a 10 de Dezembro de 1896, a estreia, numa pequena sala de vanguarda, o Teatro de l'Oeuvre, do Rei Ubu, de Alfred Jarry, caricatura monstruosa da cupidez e da crueldade de que o ser humano é capaz, dir-se-ia que premonitória, transgressora de todas as regras da moral, da lógica, da sintaxe dramática, havia desencadeado, junto do público e na imprensa, um tumulto ao pé do qual a batalha do Hernâni pouco mais era do que uma zaragata. A peça de Rostand, exaltando o heroísmo, a galanteria, o amor romântico, respeitadora das regras transgredidas por Jarry, viria reabilitar o espírito gaulês, grosseiramente ultrajado.

Para entender esta dupla reacção, há que situar Cyrano e Ubu no seu contexto epocal. Duas semanas após a criação do primeiro, Zola publica o seu agressivo manifesto "J'accuse!" em que proclama a inocência do capitão Dreyfus, iniquamente condenado por traição à pátria. A cisão aberta pelo caso na sociedade francesa finissecular agrava-se dramaticamente. A "comédia heróica" de Rostand é acolhida como um bálsamo aplicado na ferida provocada no sentimento patriótico de uma parte, a mais retrógrada e reaccionária, da população. Num outro plano, duas correntes estéticas defrontam-se nos palcos franceses: 0 naturalismo do Teatro Livre fundado havia 10 anos por André Antoine, fortemente influenciado pela doutrinação de Zola, e o simbolismo defendido pelo Teatro de l'Oeuvre, que sucedera ao Teatro de Arte criado em 1891. Cyrano situava-se a igual distância de qualquer deles - e retomava, meio século depois, a herança do romantismo historicista de Victor Hugo, Alexandre Dumas, Casimir Delavigne, com um brilhantismo e uma pericia que os poetas-dramaturgos seus contemporâneos François Coppé, Jean Richepin Théodor de Banville, não conseguiram alcançar.

Compreende-se que, perante as reacções suscitadas pela obra de Rostand, Antoine, o director do Teatro Livre, antevisse, como registou nas suas memórias, "uma catástrofe", pelo receio de que "em torno da peça se concentrassem todas as forças esparsas desde há anos contra o nosso movimento realista" (Antoine 1928: 126). 
Cyrano de Bergerac de Edmond Rostand, enc. Stephanie Shine, Stratford Shakespeare Festival, 1962

(Christopher Plummer) fot. Peter Smith
Em Setembro desse mesmo ano, e no mesmo Teatro, representava-s uma opereta de

Marcelino Mesquita, com

música de Manue Benjamim, 0 tirano da bela Urraca, em que, a parte o calemburgo do titulo, as semelhanças com a peça de Rostand são puramente fortuitas e esteriores (a cena da varanda, a localização do último quadro no pátio dum convento).
Não foi o que aconteceu: o fogo de artifício do Cyrano foi a apoteose final, o canto de cisne de um certo teatro vinculado ao passado, enquanto a farsa de Jarry significava a irrupção violenta de um outro teatro, portador do futuro. Com o Cyrano encerrava-se um ciclo, não se encetava outro. Ele foi, digamos, a explosão do drama romântico - mas, como sucede com os astros que se extinguiram, o seu brilho continua, não direi a ofuscar, mas a deslumbrarnos.

Creio ser esse o epíteto que melhor quadra a esta "comédia heróica": brilhante. Brilhante na sua expressão verbal, brilhante na sua eficácia cénica. A sua construção obedece a um sistema de palavras e gestos que se interpenetram e encadeiam de modo a produzir no espectador (ou no leitor, mas mais naquele que neste) o efeito que o autor previu. E a previsão foi, quase sempre, acertada.

Habilmente, alternam e por vezes sobrepõem-se situações heróicas e situações banais, réplicas prosaicas e tiradas líricas - numa actualização das teorias explanadas por Victor Hugo no prefácio do Cromwell sobre a mistura do sublime e o grotesco. E multiplicam-se, ao longo do texto, os morceaux de bravoure: a longa tirada sobre o nariz monumental de Cyrano, a balada que acompanha, a par e passo, o duelo no 1. acto, as estrofes sobre o beijo ("un point rose qu'on met sur l' du verbe aimer", "um ponto rosa no $i$ do verbo apaixonar", na excelente tradução de Vasco Graça Moura), a apresentação dos "cadetes de Gasconha de Carbon de Castel-Jaloux", ou a cena da varanda, no $3 .^{\circ}$ acto, em que Roxane ouve da boca de Cyrano as palavras que julga estarem a ser-Ihe dirigidas por Christian, sem que qualquer dos dois suspeite que elas são a expressão dos sentimentos do poeta-espadachim que as pronuncia... Cena admirável, que irresistivelmente nos traz à lembrança a cena equivalente do Romeu e Julieta, com menor densidade poética, sem dúvida, mas com maior eficiência dramática.

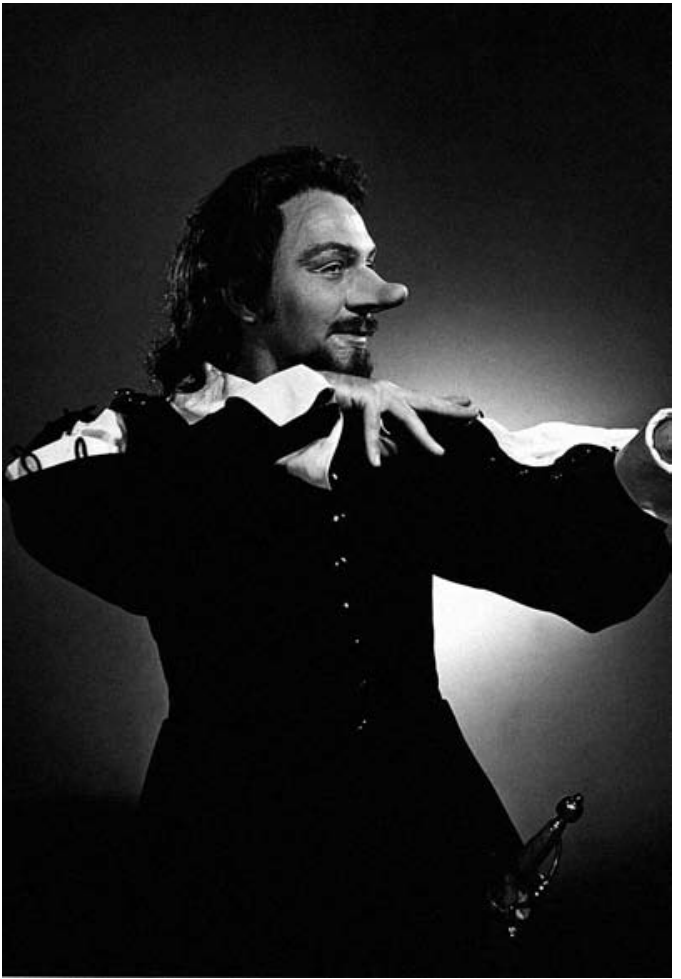

E eis que surge agora esta nova tradução portuguesa de Vasco Graça Moura, a quem se devem já outras transposições para a nossa lingua de grandes textos da dramaturgia francesa - Berenice, Fedra e Andrómaca, de Racine, 0 misantropo de Molière, e, prometido para breve, o Cid, de Corneille. É óbvio que não se pode comparar a violência passional e a fundura psicológica de Racine com o sentimentalismo lírico mas superficial de Rostand, a mordacidade satírica de Molière com a graciosa comicidade de certos momentos da "comédia heróica", o alto sentido de honra e da nobreza do Cid com o panache de Cyrano. Para quê, então, perder tempo com comparações absurdas? A peça de Rostand basta-Ihe ser o que é - e como é.

Falei em "nova tradução": explico agora o porquê do adjectivo. Como disse, Cyrano de Bergerac estreou-se em Paris num dos últimos dias de 1897. Pouco mais de seis meses depois, em Julho de 1898, uma versão portuguesa subia à cena no Teatro D. Amélia, que é hoje o Teatro São Luiz '. Assinavam-na dois jovens escritores, colegas na Escola de Medicina, então no início de uma desigual carreira literária: Júlio Dantas e Manuel Penteado. Do espectáculo sabe-se que foi da iniciativa de uma grande actriz da cena portuguesa, Lucinda Simões, criadora entre nós da Teresa Raquin de Zola, e da Madame Sans-Gêne, de Sardou - e que a personagem do espadachim gascão foi confiada ao actor Cristiano de Sousa, considerado pelo crítico de O Tempo como "de compleição débil e fraca voz" (a antítese do que o papel exigia...) e, por isso mesmo, segundo o Jornal da Noite, "falto de panache". Lucinda, nas suas memórias, limita-se a aludir a este espectáculo como tendo sido "um capricho" (Simões 1922: 187). 0 que causa espanto é a rapidez com que a peça viajou de Paris a Lisboa. Sobretudo se nos lembrarmos de que, por exemplo, Seis personagens à procura de autor, de Pirandello, uma das obras fulcrais do teatro do século $X X_{t}$ tardou quarenta anos para chegar até nós..

Perdeu-se o texto dessa tradução, mas terá sido uma 


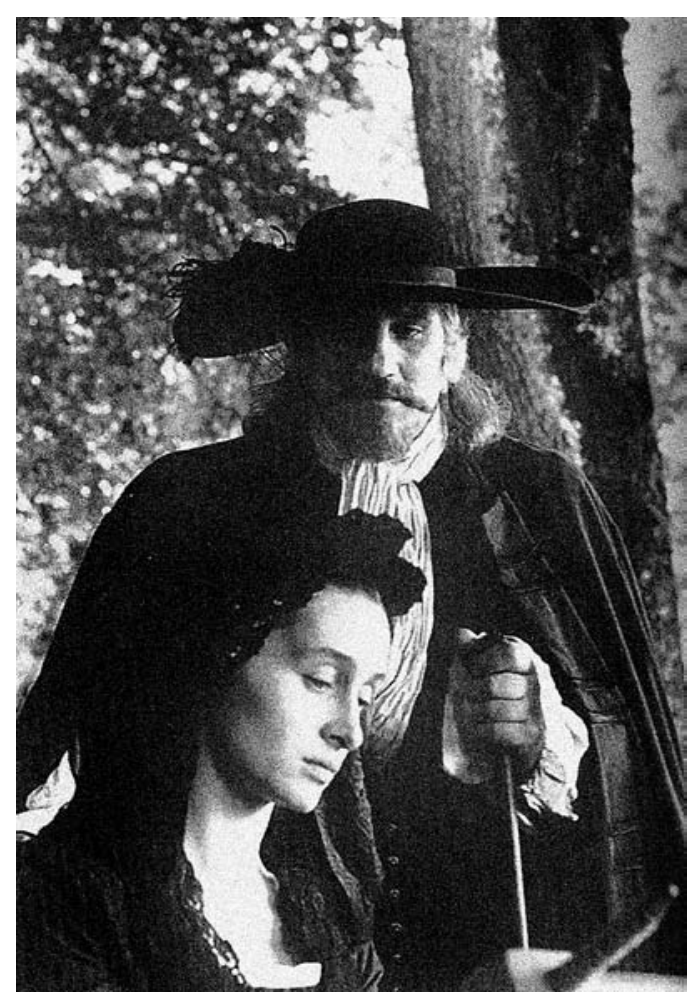

reminiscência da peça de Rostand que levou um dos tradutores, Júlio Dantas, a escrever, dois anos depois, a "comédia de capa e espada" Viriato trágico, em que o poeta e aventureiro Brás Garcia de Mascarenhas, contemporâneo de Cyrano, é apresentado como um seu possivel equivalente português.

A "comédia heróica" de Rostand voltou ao palco do mesmo Teatro D. Amélia, por duas vezes, em 1903, agora na versão original, e interpretada pelo seu criador, Constant Coquelin, um dos "monstros sagrados" da cena francesa. Da primeira vez, em Abril, representaram-se apenas o $3 .^{\circ}$ e o $5 .^{\circ}$ actos - e um crítico exigente como Joaquim Madureira escreveu que o actor francês foi "tão extraordinário, tão arrebatador, tão magistral, que nunca artista, a dentro da Declamação francesa, convencional e cantada, subiu tão alto, nas asas do génio, pelo azul infinito da Arte Divina da poesia e da emoção" (Madureira 1905: 47). 0 ano não findaria sem que Coquelin "e os coquelinos subalternos que Ihe ladram as deixas" (Madureira dixit) regressassem a Lisboa para, em 24 de Novembro, representar, agora integralmente, e ainda no mesmo palco, o Cyrano. Joaquim Madureira repetiu os encómios ao intérprete principal; mas, quanto à peça, situou-a nas suas justas proporções: "Não é uma peça que fale ao cérebro, é um poema que nos afaga os ouvidos. Não tem ideias, tem música. (...) Brilha, fulge, cintila, mas não comove, não emociona. (...) É um meteoro que perpassa, rápido (...), dando um clarão efémero ao perderse no Nada" (ibid: 174).

Acontece, porém, que esse clarão ainda hoje é visivel. A tradução de Vasco Graça Moura é, disso, a prova eloquente. Trabalho de uma terrivel complexidade - basta pensar no fraccionamento do verso alexandrino, com frequência repartido por 5, 6 e até mesmo 7 réplicas constituidas por monossilabos e dissilabos -, só um grande poeta como ele saberia encontrar as equivalências sintácticas, semânticas, linguísticas e rimáticas exigidas

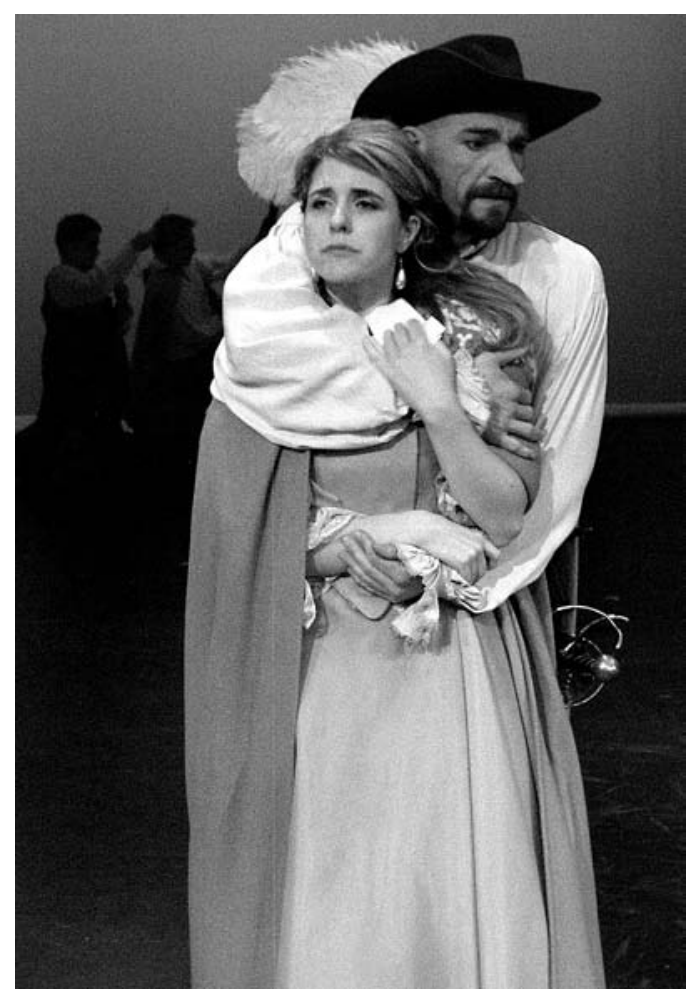

Anne Brochet e Gérard Depardieu no filme Cyrano de Bergerac, de Jean-Paul Rappeneau (1990), fot. Alain Faure.

Cyrano de Bergerac, de Edmond Rostand, enc. Stephanie Shine, Seattle Shakespeare Company, 2006 (Scott Coopwood e Emily Grogan), fot. Erik Stuhaug.
- ou seja, estabelecer a conciliação entre o sistema literário e cénico de partida e o sistema literário e cénico de chegada, preservando aquele e integrando-o neste. É que traduzir, e muito especialmente no caso da tradução teatral, não é transcrever nem reproduzir, é antes reescrever, recriar. Uma tradução fiel não é, necessariamente, uma boa tradução, nem uma boa tradução é, necessariamente, uma tradução fiel. Como oportunamente lembra Umberto Eco, "a fidelidade é a tendência para crer que a tradução é sempre possivel se o texto-fonte tiver sido interpretado com apaixonada cumplicidade, é um empenho em identificar o que para nós é o sentido profundo do texto e a capacidade de negociar a cada instante a solução que nos parece mais certa. Se se consultar qualquer dicionário, ver-se-á que entre os sinónimos de 'fidelidade' não se encontra a palavra 'exactidão'. Em vez dela o que lá está é 'lealdade', 'honestidade', 'respeito'..." (Eco 2005: 376).

É essa "apaixonada cumplicidade", esse "empenho em identificar o sentido profundo do texto", essa "capacidade de negociar a solução mais certa", essa lealdade, esse respeito pelas intenções do autor originário, que credibilizam esta notável tradução de Vasco Graça Moura e transferem o Cyrano de Bergerac de Rostand para o património dramatúrgico português.

\section{Referências bibliográficas}

ANTOINE, André (1928), Mes souvenirs sur le Théâtre Antoine et l'Odéon, Paris.

ECO, Umberto (2005), Dizer quase a mesma coisa sobre tradução, trad. José Colaço Barreiros, Lisboa, Difel.

La Petite Illustration - Théâtre, n. ${ }^{\circ}$ 454, Paris, 1939.

MADUREIRA, Joaquim (1905), Impressões de theatro, Lisboa, Ferreira \& Oliveira.

SIMÕES, Lucinda (1922), Memórias: Factos e Impressões, Rio de Janeiro,

Fluminense. 